\title{
Dengue fever with hemorrhagic manifestations in travellers returning to Quebec from Asia
}

\author{
RAYMOND DuperVAl, MD, ERIC H Frost, PhD, HARVEY ARTSOB, PHD
}

\begin{abstract}
R Duperval, EH Frost, H ARTSOB. Dengue fever with hemorrhagic manifestations in travellers returning to Quebec from Asia. Can J Infect Dis 1993:4(4):220-222. Two cases of dengue fever with hemorrhagic manifestations were observed in 1990 and 1992 among travellers returning from Asia, while a third presented with classical dengue fever after the patient's first trip to an endemic region. All experienced rash, thrombocytopenia and coagulation disorders and had flavivirus serology consistent with exposure to dengue virus.
\end{abstract}

Key Words: Coagulation disorders, Dengue virus, Thrombocytopenia

\section{Fièvre dengue avec manifestations hémorragiques chez des voyageurs québécois revenant de l'Asie}

RÉSUMÉ: Deux cas de fièvre dengue avec manifestations hémorragiques furent observés en 1990 et 1992 chez des Québécois ayant séjournés en Asie. Un troisième malade s'est présenté avec une fièvre dengue classique après un premier voyage dans une région endémique. Tous les trois ont présenté une éruption cutanée, une thrombocytopénie, des anomalies des paramètres de coagulation, ainsi que des résultats sérologiques compatibles avec une exposition au virus de la fièvre dengue.

$\mathrm{D}$ ENGUE FEVER IS CAUSED BY ANY OF FOUR SEROTYPES of mosquito-transmitted flaviviruses known as dengue 1, 2, 3 and 4 viruses (1). Dengue is highly endemic in tropical regions of the Americas, Africa, Asia and Oceania, with an annual infection rate of $10 \%$ for endemic regions (2). Symptomatic infections occur primarily in children. Although symptoms are usually mild, more severe forms such as dengue hemorrhagic fever (DHF), and the most severe form, dengue shock syndrome (DSS), can be distinguished from classic dengue fever by the presence of thrombocytopenia with concurrent hemoconcentration and positive tourniquet test (3). DHF and DHF/DSS are usually observed only in Asian infants or children who are immune to one serotype of dengue virus and are experiencing infection with a second serotype $(1,2,4)$. Hemorrhagic manifestations less severe than those associated with DHF can also be observed in classic dengue fever in about $4 \%$ of

Department of Infectious Diseases and Microbiology. Centre hospitalier universitaire de Sherbrooke, Sherbrooke, Québec; and Zoonotic Diseases, National Laboratory for Special Pathogens, Laboratory Centre for Disease Control, Ottawa, Ontario

Correspondence and reprints: Dr Raymond Duperval, Service des maladies infectieuses, Centre hospitalier universitaire de Sherbrooke, Sherbrooke, Québec JIH 5N4. Telephone (819) 563-5555

Received for publication June 8, 1992. Accepted November 26, 1992 
cases (5) although some outbreaks are associated with a higher percentage of hemorrhagic complications (6).

Although not endemic in Canada, several infections with dengue virus are generally recognized each year in Canadians who have travelled abroad (7). We report the first two cases of dengue fever with hemorrhagic manifestations (occurring in 1990 and 1992) observed in the 22-year history of the Centre hospitalier universitaire of Sherbrooke and discuss the distinction of this syndrome from DHF. A third case of dengue complicated with thrombocytopenia was observed in a patient returning from his first trip to a region endemic for dengue virus.

\section{CASE ONE}

A 37-year-old man, five days after returning from a two-week trip to Korea, Hong Kong and the Philippines, presented with unrelenting fever $\left(39\right.$ to $40^{\circ} \mathrm{C}$ ) for four days, backache, dry cough and prostration. Physical examination disclosed hepatosplenomegaly. Prior to this trip in September 1990, he had visited Venezuela in 1981. Twenty-four hours after hospitalization, a macular rash developed on the thorax and arms followed the next day by a purpuric rash first on the legs, becoming generalized the following day. Initially he noted a metallic taste in his mouth. Three negative thick and thin films and normal hematocrit ruled out malaria. Three hemocultures were also negative. Leukocytopenia ( 2500 white blood cells $/ \mathrm{mL}$ ) at admission gradually returned to normal values. Marked thrombocytopenia $(59,000 / \mathrm{mL})$ continued to fall until the second day of hospitalization $(43,000 / \mathrm{mL})$ and increased slowly to attain normal values on day 5 . Other coagulation parameters (normal values follow in parentheses) showed the following: prothrombin time, $14.8 \mathrm{~s}$ (12 to $15 \mathrm{~s}$ ); activated partial thromboplastin time, $48.8 \mathrm{~s}$ (23 to $35 \mathrm{~s}$ ), fibrin split product 80 to $120 \mathrm{mg} / \mathrm{L}(0 \mathrm{mg} / \mathrm{L})$. Fibrinogen was normal and total protein was decreased to $53 \mathrm{~g} / \mathrm{L}$ ( 60 to $80 \mathrm{~g} / \mathrm{L}$ ). Seroconversion consistent with recent dengue infection was documented (Table 1). Clinical course was uneventful and all laboratory abnormalities returned to normal within five days after admission.

\section{CASE TWO}

A 44-year-old man presented to hospital with fever, chills, dry cough, diarrhea and prostration for the three days following his return from a five-and-a-half-week trip through Thailand, Nepal and India. In the previous year, he had visited the same three countries. A macular rash was observed principally on the back but also on the thorax. Two negative thick and thin films and a normal hematocrit eliminated malaria. Three hemocultures were negative. Leukopenia persisted for the first four days of hospitalization while thrombocytopenia attained its nadir $(51,000 / \mathrm{mL})$ on the third and fourth days before returning to normal. Coagulation para-
TABLE 1

Flavivirus* serology of dengue patients

\begin{tabular}{|c|c|c|c|}
\hline & \multicolumn{3}{|c|}{$\begin{array}{l}\text { Reciprocal antibody titres by } \\
\text { hemagglutination inhibition }\end{array}$} \\
\hline & $\begin{array}{l}\text { St Louis } \\
\text { encephalitis }\end{array}$ & Powassan & Dengue \\
\hline \multicolumn{4}{|l|}{ Case 1} \\
\hline Serum 05/09/90 & 320 & 40 & 160 \\
\hline Serum 06/09/90 & 2500 & 160 & 640 \\
\hline Serum 25/09/90 & 2560 & 2560 & 10,240 \\
\hline \multicolumn{4}{|l|}{ Case 2} \\
\hline Serum 30/01/92 & 80 & 40 & 20 \\
\hline Serum 12/02/92 & $>10,240$ & 5120 & 1280 \\
\hline \multicolumn{4}{|l|}{ Case 3} \\
\hline Serum 31/01/92 & 1280 & 160 & 320 \\
\hline Serum 26/02/92 & 640 & 160 & 320 \\
\hline
\end{tabular}

*No hemagglutination inhibiting antibodies were detected to the following alphaviruses: eastern equine encephalitis, western equine encephalitis, Chikungunya, Semliki Forest and Sindbis

meters showed normal prothrombin time, increased activated partial thromboplastin time to $40.4 \mathrm{~s}$ (normal 23 to $35 \mathrm{~s}$ ), normal fibrinogen and no fibrin split products. Total protein was decreased to $57 \mathrm{~g} / \mathrm{L}$ (63 to $82 \mathrm{~g} / \mathrm{L}$ ). Seroconversion consistent with recent dengue infection was documented (Table 1). No bleeding was noticed except for slight epistaxis on day 3 . The laboratory tests returned to normal on the seventh day after admission.

\section{CASE THREE}

An 18-year-old man had accompanied his father (case 2) on his second but not his first trip to Asia. He also reported with fever but in addition had headache and retro-orbital pain. His macular rash was more discrete but was noted already on his arms and legs at admission five days after returning home. Two negative thick and thin films together with a normal hematocrit and three negative hemocultures ruled out malaria and bacterial causes. Moderately elevated alanine aminotransferase (339 IU/L, normal 7 to 56 IU/L) and aspartate aminotransferase (316 IU/L, normal 5 to $40 \mathrm{IU} / \mathrm{L}$ ) values gradually returned to normal at follow-up three weeks later. Serology for hepatitis viruses A, B and C was negative. Leukopenia was slight (4100 white blood cells $/ \mathrm{mL})$. Thrombocytopenia $(78,000 / \mathrm{mL})$ returned to normal on day 4 of hospitalization. Coagulation parameters were normal except for activated partial thromboplastin time which was slightly increased to $36.8 \mathrm{~s}$ (normal 23 to 35 s). Serology was consistent with exposure to dengue but an unequivocal seroconversion was not observed (Table 1).

\section{DISCUSSION}

Undoubtedly these three patients had more severe forms of dengue fever than the classical syndrome. The first two cases had marked thrombocytopenia and spontaneous bleeding (albeit epistaxis was slight in 
case 2). The third patient probably had classical dengue fever with greater thrombocytopenia than is usually observed. Although thrombocytopenia (fewer than $100 \times 10^{9}$ platelets/L) is not a typical feature of classic dengue fever (8), it is occasionally observed. By itself, thrombocytopenia is not sufficient to define DHF unless accompanied by hemoconcentration (hematocrit increased by $20 \%$ or more) and a positive tourniquet test (3). DHF can be further categorized into four grades: grade 1 is accompanied only by a positive tourniquet test; grade 2 is recognized when spontaneous bleeding is present; grades 3 and 4 are defined by different degrees of shock and are termed DHF/DSS (3). By exclusion, other dengue fever virus infections can be classified as dengue fever with or without hemorrhagic manifestations.

In a large study of patients hospitalized in the Philippines for fever and hemorrhagic manifestations, 110 confirmed cases of DHF (mostly grade 2) were seen together with 355 cases of dengue fever with hemorrhagic manifestations, indicating that this latter syndrome is observed slightly more often than DHF (9). Thrombocytopenia was observed in $72 \%$ of these patients (9) and in a similar percentage of dengue fever patients with hemorrhagic manifestations from Fiji (10).

The severity of the symptoms we observed in the first two patients was more remarkable in that they occurred in patients over 25 years of age, who account for less than $2 \%$ of the hospitalized patients in the study from the Philippines (9). Even in the South Pacific where fatal adult cases of DHF have been observed (10), the risk of dengue-like illness among persons over 30

ACKNOWLEDGEMENTS: The authors greatly appreciate the secretarial skills of Ann McGee and the technical expertise of Barbara Calder-Kent.

\section{REFERENCES}

1. Gubler DJ. Dengue. In: Monath TP, ed. The Arboviruses: Epidemiology and Ecology. Boca Raton: CRC Press, 1988:223-60.

2. Halstead SB. Pathogenesis of dengue: Challenges to molecular biology. Science 1988;239:476-81.

3. Dengue Hemorrhagic Fever: Diagnosis, Treatment and Control. Geneva: World Health Organization, 1986.

4. Monath TP. Flavivirus (yellow fever, dengue and St Louis encephalitis). In: Mandell GL, Douglas RG Jr, Bennet JE, eds. Principles and Practice of Infectious Diseases, 3rd edn. New York: Churchill Livingstone Inc, 1990:1248-51.

5. Johnson K, Halstead SB, Cohen S. Hemorrhagic fevers of Southeast Asia and South America: A comparative appraisal. Prog Med Virol 1967;9:105-58.

6. Reed D, Maguire T, Mataika J. Type 1 dengue with was lower than for those under 30 years of age (6). Hemorrhagic phenomena were rare among American servicemen infected with dengue viruses during World War II and the Vietnam War (11). Our observation of more severe forms of dengue virus infection among returned travellers may reflect increasing virulence for nonindigenous populations.

The first two cases showed a clear seroconversion to all three flaviviruses tested highlighting the frequent cross-reactions between these viruses that are typical of flavivirus infections, particularly when using the hemagglutination inhibition test. The high titres and rapid increase in antibody titres observed in case 1 are characteristic of secondary flavivirus infections (7).

The third case showed lower, invariant titres to the three viruses. It is probable that the milder infection was already resolving and the seroconversion had already occurred when the patient presented to hospital (rash was already evident and platelet and coagulation parameters did not decrease during hospitalization, as was observed in the other two patients, but rapidly returned to normal). As this was the patient's first trip to a region endemic for dengue virus, it is unlikely that his antibody titres reflect an infection incurred previous to this voyage.

We report these three cases to emphasize that not only dengue, but dengue fever with hemorrhagic manifestations, may be encountered among the increasing number of international travellers. We are aware of only one other published report (9) of a case of dengue fever with hemorrhagic manifestations (mistakenly termed dengue hemorrhagic fever) recognized in Canada (12).

hemorrhagic disease in Fiji: Epidemiologic findings. Am J Trop Med Hyg 1977;26:784-91.

7. Artsob H, Spence L. Imported arbovirus infections in Canada 1974-89. Can J Infect Dis 1991;2:95-100.

8. Halstead SB. Dengue hemorrhagic fever - A public health problem and a field for research. Bull World Health Organ 1980;58:1-21.

9. Hayes CG, Manalotto CR, Gonzales A, Ranoa CP. Dengue infections in the Philippines: Clinical and urological findings in 517 hospitalized patients.

Am J Trop Med Hyg 1988;39:110-6.

10. Kuberski T, Rosen L, Reed D, Mataika J. Clinical and laboratory observations on patients with primary and secondary dengue type 1 infections with hemorrhagic manifestations in Fiji. Am J Trop Med Hyg 1977;26:775-83.

11. Halstead SB. Different dengue syndromes - The perspective from a pathogenetic point of view. Asian $\mathrm{J}$ Infect Dis 1978;2:59-65.

12. Spigelblatt L, Rosenfeld R, Bonny Y, Laverdiere M. Dengue hemorrhagic fever in North America: A case report. Pediatrics 1980;66:631-3. 


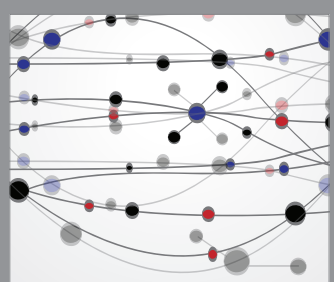

The Scientific World Journal
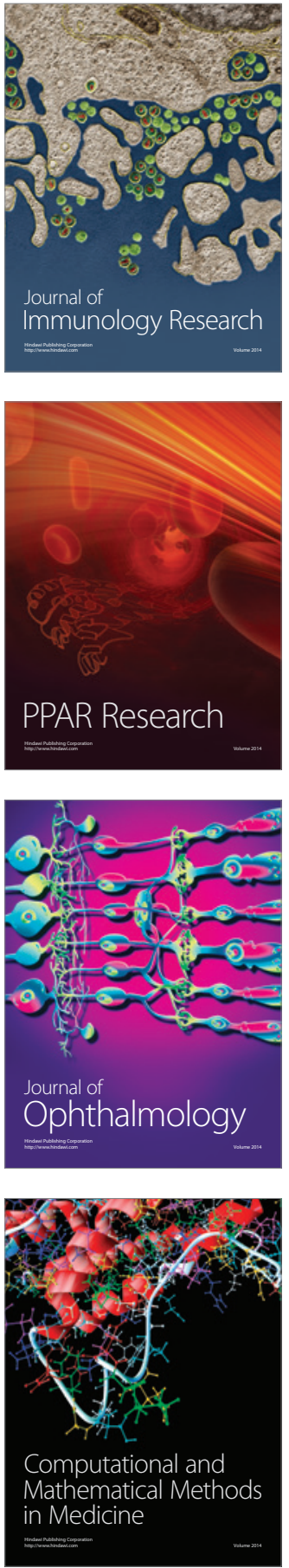

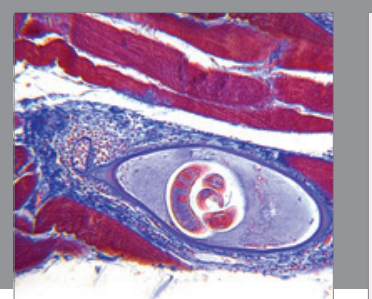

Gastroenterology Research and Practice

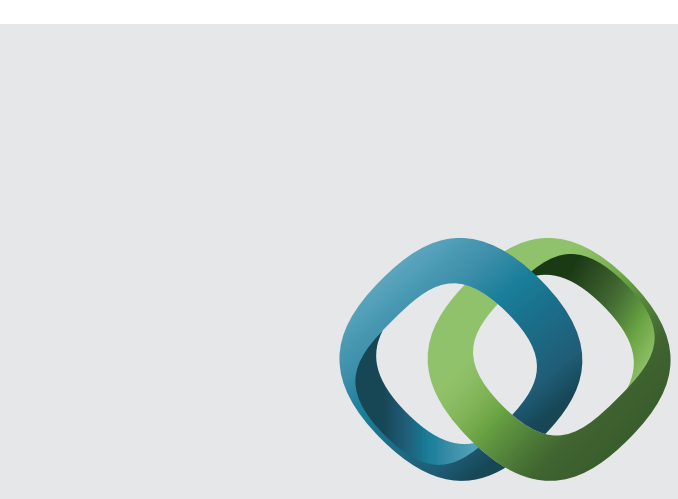

\section{Hindawi}

Submit your manuscripts at

http://www.hindawi.com
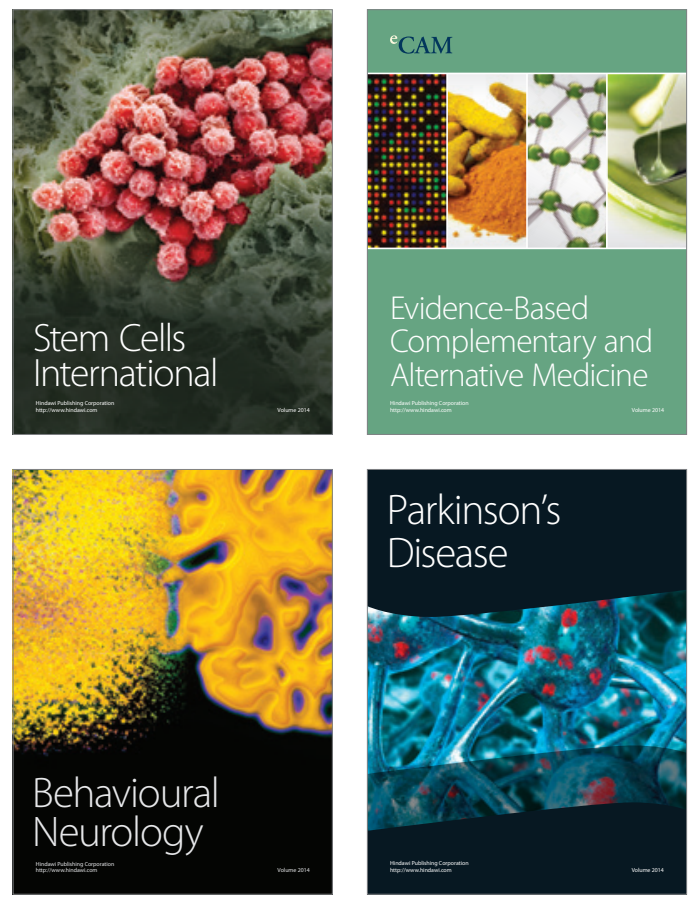
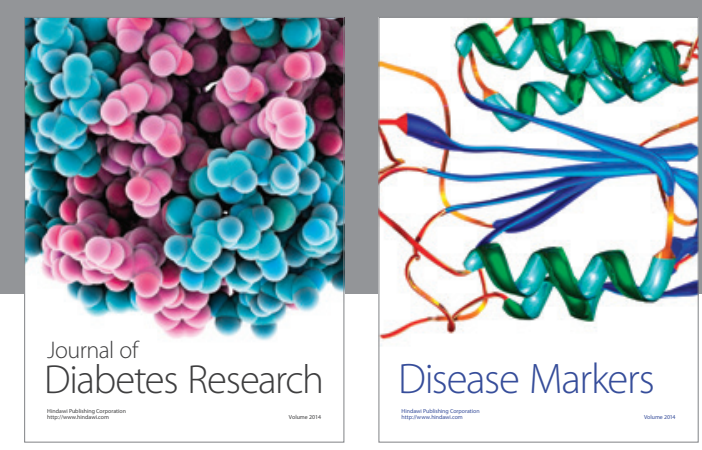

Disease Markers
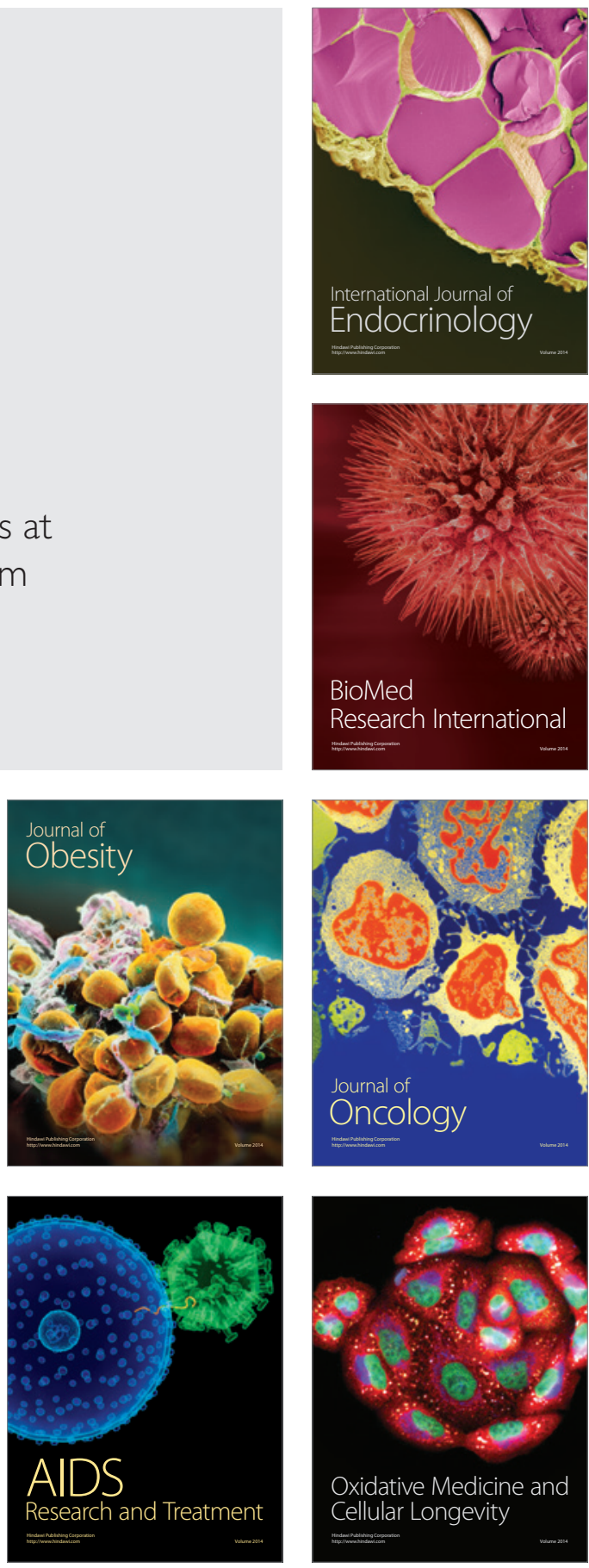